\title{
Review \\ Toll-like receptors and innate immune responses in systemic lupus erythematosus
}

\author{
Robert Lafyatis ${ }^{1}$ and Ann Marshak-Rothstein ${ }^{2}$
}

\begin{abstract}
${ }^{1}$ Boston University School of Medicine, Department of Medicine, Rheumatology Section, 715 Albany Street, Boston, Massachusetts 02118, USA
${ }^{2}$ Boston University School of Medicine, Department of Microbiology, 715 Albany Street, Boston, Massachusetts 02118, USA
\end{abstract}

Correspondence: Robert Lafyatis, lafyatis@bu.edu

Published: 29 November 2007

This article is online at http://arthritis-research.com/content/9/6/222

(C) 2007 BioMed Central Ltd
Arthritis Research \& Therapy 2007, 9:222 (doi:10.1186/ar2321)

\begin{abstract}
A series of discoveries over the past several years has provided a new paradigm for understanding autoimmunity in systemic lupus erythematosus. The discoveries of pattern recognition receptors and of how these receptors can be recruited into autoimmune responses underpin this paradigm. The implications of these observations continue to unfold with ongoing investigation into the range and specificity of pattern recognition receptors, into how immune complexes containing nucleic acids trigger these receptors, into how endogenous macromolecular 'danger signals' stimulate innate immune responses, and into the effect of pattern recognition receptor activation on various cell types in initiating and perpetuating autoimmunity. The development of clinical trials using therapeutic agents that target components of the innate immune system suggests that these advances may soon culminate in new medications for treating patients with systemic lupus erythematosus.
\end{abstract}

\section{Introduction}

Pattern recognition receptors are the key to innate immune system recognition of microbes. The strength of these receptors in terms of their ability to respond to molecular motifs common to pathogens may also prove to be the weakness that results in autoimmunity, because they are potentially less discrete than the cognate immune system in distinguishing self from nonself. The most important pattern recognition receptor family of receptors involved in lupus, namely the Toll-like receptors (TLRs), can recognize a broad range of microbial components, including DNA and RNA. In this review we consider the implications of multiple studies showing how these receptors play key roles in autoimmunity in patients with systemic lupus erythematosus (SLE).

\section{Autoantibodies}

Autoantibodies to DNA, RNA, and associated proteins represent a central puzzle in SLE pathogenesis. They are common targets of the autoimmune response, but the stimulus for their formation and their roles in pathogenesis have been obscure. Although exposed protein targets, such as $\beta_{2}$-glycoprotein I and red blood cell or platelet surface proteins, can be readily implicated in pathogenesis, antibodies to nucleic acids also appear to contribute to pathology. Most notably, anti-DNA antibodies are associated with disease severity in lupus nephritis, deposit in renal tissues, crossreact with renal antigens, and can induce nephritis in mice. Anti-DNA antibodies can also crossreact with the anti- $N$-methyl-D-aspartate receptor and may cause cognitive dysfunction or depression in lupus patients $[1,2]$. Other common targets of antinuclear antibodies include proteins that bind to DNA and RNA [3]: histone proteins bind and package DNA, Sm proteins bind U RNAs and direct mRNA splicing, and Ro protein binds $Y$ RNAs and recognizes misfolded RNAs.

\section{Adaptive immunity and autoantibody formation}

A common theme of autoantigens in SLE is their association in intermolecularly linked complexes associated with nucleic acids. Autoantibodies target multiple regions of autoantigens and have undergone affinity maturation, suggesting that their production is aided by the adaptive immune response. The adaptive immune response to small nuclear RNP (snRNP) proteins has shown that B-cell epitope spreading can occur, such that immunization of a peptide from Sm B/B' can result in autoantibodies to other Sm proteins [4]. Autoreactive T-cell help is critical in epitope spreading [5], and immunization with an immunodominant T-cell epitope, generating autoreactive T cells, can stimulate autoreactive $B$ cells reactive with intermolecularly linked determinants [6]. Crossreactivity has also been implicated in epitope spreading, particularly the recruitment of $B$ cells reactive with autoantigens that are not

$\mathrm{CDC}=$ conventional dendritic cell; $\mathrm{DC}=$ dendritic cell; $\mathrm{Fc} \gamma \mathrm{R}=\mathrm{Fc} \gamma$ receptor; HMGB $=$ high mobility group box; IFN $=$ interferon; IL $=$ interleukin; $\mathrm{MFG}-\mathrm{E}=$ milk fat globule-epidermal growth factor; $\mathrm{pDC}=$ plasmacytoid dendritic cell; RAGE = receptor for advanced glycation end-products; SLE = systemic lupus erythematosus; snRNP = small nuclear RNP; snoRNP = small nucleolar RNP; Th1 = T-helper-1; TLR = Toll-like receptor; TNF = tumor necrosis factor; $Y a a=Y$-linked autoimmune accelerator. 
molecularly linked to the immunizing peptide, such as Ro and La [7].

Unlike protein antigens, nucleic acids cannot be processed to components recognized by $T$ cells. However, as for protein autoantigen targets, antibodies to nucleic acids (anti-DNA antibodies) exhibit somatic mutations, suggesting T-cell help in their generation. It is most likely that T-cell help is directed to histones or other DNA-binding proteins in DNA-containing nucleosomes [8]. Thus, adaptive immune responses can target both DNA and RNA-containing molecular complexes. Importantly, complexes taken up by antigen-presenting cells can stimulate autoreactive $T$ cells to help $B$ cells reactive with either proteins or nucleic acids within the complex.

\section{The innate immune system in autoantibody production} In virtually all studies of induced murine autoimmunity, adjuvant is required to initiate the immune response to autoantigens or derived peptides. In many if not all cases, these adjuvants are innate immune stimuli. Furthermore, although adaptive immune responses can explain such phenomena as epitope spreading and the observed presence of autoantibodies against intermoleculary linked protein complexes, innate immune mechanisms also contribute to such events. In addition, innate immune system activation provides the most ready explanation for highly increased IFN-regulated gene expression observed in leukocytes from SLE patients. These and other observations discussed below indicate that innate immune recognition plays a key role in the initial development and amplification of the immune response to both nucleic acid and nucleic acid binding autoantigens. Indeed, in the enthusiasm with which the immune system eliminates microbes, these autoantigens may represent an Achilles heel of overactivity; the critical stimulants of the innate immune system in SLE patients may be nucleic acid/protein complexes, which can serve as both immunogens and adjuvants.

\section{Innate immune sensors}

The nucleic acid binding TLRs appear to play pivotal roles in SLE. TLR7 and TLR8 bind to single-stranded RNA, TLR3 to double-stranded RNA, and TLR 9 to DNA. These receptors are intracellular and are engaged by their ligands in a cytoplasmic compartment of the endoplasmic reticulum-endosome-lysosome lineage [9]. Engagement of these receptors provides a mechanism for host responses to nucleic acids, and ultimately for the production of autoantibodies to nucleic acids and proteins bound to nucleic acids. Disruption of this signaling may be a major mechanism of action of antimalarial agents, which inhibit nucleic acid TLR signaling in vitro by blocking endosomal maturation $[10,11]$.

\section{DNA and Toll-like receptor 9 activation}

Several mechanisms serve to promote the specificity of responses to nucleic acids, so that innate immune cells sense and respond to viral and bacterial but not host nucleic acid. This is best understood for DNA. Hypomethylated CpG- containing DNA selectively activates TLR9. CpG motifs in mammalian DNA are relatively rare and generally methylated, so that mammalian DNA is a weak TLR9 agonist [12]. In addition, mammalian DNA contains sequences that suppress TLR9 activation [13]. Further suggesting the importance of DNA methylation and TLR9 in autoimmunity, two common medications frequently associated with drug-induced SLE, namely hydralazine and procainamide, inhibit DNA methylation [14]. These observations help to explain why mammalian DNA does not normally activate the immune system. In lupus sera, however, seminal observations indicate that circulating immune complexes (ICs) containing DNA stimulate dendritic cell (DC) production of type I IFNs [15]. How DNA becomes an immune adjuvant therefore remains a central question in lupus pathogenesis.

\section{RNA and Toll-like receptor $7 / 8$ activation}

Parallel studies have investigated the role of RNA-containing ICs in innate immune system activation. Lupus sera incubated with apoptotic cell debris exhibit IFN-inducing activity associated with anti-RNP reactivity rather than anti-DNA activity [16]. TLR7 is activated by single-stranded RNA containing $U$ and $G$ rich motifs $[17,18]$. Thus, highly U/G-rich $\mathrm{U}$ and $\mathrm{Y}$ RNAs bound respectively to snRNP and Ro/La autoantigens both stimulate TLR7 and/or TLR8 [19]. Methylated or modified nucleosides found frequently in mammalian RNAs markedly decrease the activity on TLR7 activation [20], suggesting that, as for DNA, mammalian RNA modifications permit a degree of selectivity for responses by innate immune receptors to pathogens. Why and how, then, do these mammalian nucleic acids become endogenous TLR activators?

\section{Endogenous ligands of Toll-like receptor activation}

Recent studies have shown that autoantibody-nucleic acid complexes from SLE patents are able to act as endogenous immune adjuvants and shed light on the mechanisms of IC internalization. Early work showed that sera from lupus patients contain a soluble factor that stimulates leukocytes to secrete IFNs [15]. These studies suggested that the circulating factor might include DNA in ICs and fit well with data showing that CpG DNA oligonucleotides can enter cells and stimulate TLR9. Other studies showed that singlestranded RNA stimulates TLR7 and TLR8 [18], suggesting that RNA-containing ICs might stimulate these TLRs.

More recent work has clarified how ICs containing nucleic acid can enter cells, stimulate TLRs, and thereby provoke an immune response. Before DNA can activate TLR9 or RNA activate TLR7 and TLR8, they must enter the proper intracellular compartment. The B-cell receptor was shown to mediate TLR9 activation using $B$ cells from rheumatoid factor transgenic mice (AM14 cells) [21]. These studies were extended to show that haptenated DNA could bind to and stimulate TLR9 in B cell expressing hapten-specific receptors [22], further clarifying that autoantigens bound by the B-cell receptor can be delivered to the proper intracellular compartment to trigger TLR9 activation. 
These $B$ cells were found to proliferate in response to hypomethylated DNA/anti-DNA ICs, but only certain DNA sequences promoted robust responses [22].

Subsequent work showed that $F_{c}$ receptors on DCs (plasmacytoid dendritic cells $[\mathrm{pDCs}]$ ) can bind to the immunoglobulin Fc component of nucleic acid containing ICs, internalize the ICs, and deliver the nucleic acid component to intracellular TLRs. The importance of Fc receptors on DCs was first suggested in the IFN production by human pDCs induced by SLE sera in the presence of apoptotic cells. Blocking the high-affinity $\mathrm{Fc} \gamma$ receptor (FcyR)II/CD32 inhibited IFN production [23]. FcyRII/CD32 on pDCs was subsequently shown to be required for IFN production and to co-localize with TLR9 after exposure to DNA-containing ICs [24]. In murine myeloid DCs, FcyRIII was required for DNA IC activation [25]. Although these studies showed that DNA/anti-DNA complexes can stimulate TLR9, similar mechanisms indicate that RNAbinding proteins such as snRNPs can participate in a similar mechanism, because incubation with snRNP ICs stimulates TLR7-dependent IFN production by pDCs $[19,26]$.

\section{Effector mechanisms of innate immune stimulation in systemic lupus erythematosus}

Different immune cell types express different subsets of TLRs. In addition, the effects of TLR stimulation depend not only on the specific TLR activated but also on the cell type expressing the TLR. In SLE the roles of TLR activation in B cells and DCs are the most evident; the effects of TLR activation in these cell types (autoantibody and IFN production) are clearly implicated in SLE pathogenesis.

\section{Toll-like receptor activation of $B$ cells}

Normal individuals have circulating $B$ cells that contain a substantial percentage of autoreactive specificities [27], providing a large pool of autoreactive $B$ cells that might be activated through protein/nucleic acid ICs. Oligonucleotide TLR9 agonists, and TLR7 agonists after exposure to IFN- $\alpha$ can activate both memory and naïve $B$ cells, resulting in class switching and maturation into immunoglobulin-secreting plasmablasts [28-30]. TLR-stimulated B-cell activation may also contribute to SLE pathogenesis through mechanisms that do not directly involve autoantibody production, such as antigen presentation or cytokine production [31].

\section{Toll-like receptor activation of dendritic cells}

DCs include several cell types. Traditional or myeloid DCs can be found in the circulation, and an apparently similar cell type can be derived from monocytes by treatment in vitro. These cells reside in peripheral tissues where their primary role appears to be antigen processing and presentation. A second more recently recognized $D C$ is the $\mathrm{pDC}$. These latter cells appear particularly important in the innate immune dysfunction in SLE. Although they represent a small population of circulating mononuclear cells, these cells are the dominant source of type I IFNs [32,33]. They harbor both
TLR7 and TLR9 receptors and are exquisitely sensitive to RNA and DNA stimulation.

Conventional DCs (cDCs) express and respond to TLR stimuli and might promote autoimmunity by affecting $\mathrm{T}$-cell help. TLR7/8 in combination with TLR3/4 activation or IL-4 stimulate IL-12 secretion by CDCs, promoting T-helper-1 (Th1) T-cell differentiation [34]. TLR-elicited functions can also be modified by co-engagement of non-TLR receptors. For example, stimulation with experimental ligands, such as CpG oligonucleotides, induces murine cDCs to secrete IL-12 as well as tumor necrosis factor (TNF)- $\alpha$, whereas chromatin ICs promote only secretion of TNF- $\alpha$ [25]. These latter results emphasize the potentially important differences in cellular responses to synthetic oligonucleotides compared with naturally occurring TLR ligands. Monocytes can also be induced to secrete IL-12 through a combination of TLR4 and TLR8 stimulation [34]. Thus, TLR activation by nucleic acid containing ICs can act alone or as co-stimulants for IL-12 secretion and Th1 cell skewing. Although the effects of such skewing on autoimmunity are not entirely clear, IFN- $\gamma$ (a major product of Th1 cells) contributes to nephritis in murine lupus models $[35,36]$.

\section{Type I interferons in systemic lupus erythematosus}

The importance of type I IFNs in lupus pathogenesis has emerged from several observations, led by microarray analyses of gene expression of leukocytes from lupus patients $[37,38]$. Leukocytes from lupus patients exhibit highly increased expression of a wide variety of genes that are known to be upregulated by IFNs. This effect appears to be mediated by IFN- $\alpha$ subtypes secreted prominently by pDCs. A prominent role for type I IFNs in lupus was further suggested by the occasional development of autoimmunity and lupus in patients treated with IFN for hepatitis $\mathrm{C}$ infection.

IFN production is normally a feature of the immune response to microbial infections and has multiple effects on the immune system. Type I IFNs stimulate monocyte maturation into DCs, plasma cell maturation and immunoglobulin class switching, cytotoxic $\mathrm{T}$ and natural killer cell activity, and chemokine secretion. Type I IFNs also highly upregulate TLR7 expression, providing a strong positive feedback loop that might perpetuate autoimmunity to RNA-associated autoantigens. Although type I IFNs can stimulate these effects, which would be expected to promote autoimmunity, the role of type I IFNs in human disease remains incompletely understood, given the unexpected disease found in certain autoimmune prone, IFN receptor deleted mice [39]. In addition, the relative importance of these various effects in lupus pathogenesis is unknown and other inflammatory cytokines stimulated by TLR activation, such as TNF- $\alpha$ and IL-6, may also play key roles.

\section{Cellular debris and immune clearance}

A likely source of intracellular antigens for immune stimulation in SLE became clear with the appreciation that ongoing cell 
death in the body provides a constant burden of cellular debris that must be cleared from the circulation [40]. Cells can die in different ways, including apoptosis, necrosis, and autophagy. Of these mechanisms, apoptosis has been most clearly implicated in human lupus and murine lupus models. Mice injected with apoptoic cells in the absence of adjuvant produce autoantibodies, including antibodies to DNA [41], whereas mammalian DNA alone has no activity [42]. These observations suggest that cell death provides a change in chromatin structure or composition that promotes an immune response, or that apopototic DNA is delivered to a different intracellular compartment than 'free' DNA. The molecular mechanisms that lead to this change remain unclear even as the process of clearing apoptotic debris has become better understood.

\section{Cell death and autoimmunity}

Apoptosis is associated with the redistribution of phosphatidylserine, normally an internal membrane lipid, to the cell surface. Incompletely identified receptors for phosphatidylserine and several other ligand-receptor pairs help phagocytes to recognize apoptotic cells and remove them from the circulation $[40,43]$ through sequential tethering and engulfment. Particularly notable with regard to autoimmunity are complement, secretory lgM, milk fat globule-epidermal growth factor (MFG-E) 8 and tyro 3 kinases, because alterations in these proteins are associated with autoimmunity. Apopotic cells express binding sites for $\mathrm{C} 1 \mathrm{q}$ and $\mathrm{C} 3 \mathrm{~b} / \mathrm{bi}$ that can bind to the CR3 and CR4 complement receptors. C1q deletion leads to glomerulonephritis and is associated with increased numbers of apoptotic cells [44]. C3b/bi associates with phosphatidyserine on apoptotic cells and binds to C3 and C4 complement receptors on macrophages, facilitating apoptotic cell clearance [45]. These observations are particularly intriguing in light of the known complement deficiencies associated with human lupus. Natural IgM autoantibodies facilitate complement binding [46]. MFG-E8 also associates with phosphatidylserine, and its deletion leads to decreased apoptotic cell clearance in lymphoid organs, autoantibodies, and glomerulonephritis [47].

Apoptotic cells are thought to result in 'silent death', in the sense that an important feature of this regulated process is to allow effective disposal without immune activation. Antiinflammatory effects of apoptotic cells are mediated through phagocyte production of transforming growth factor- $\beta$ and IL-10. In addition, Gas-6 on apoptotic cells binding to receptor kinases of Tyro 3 family (mer, tyro and axl) downregulate inflammatory cytokines, $\mathrm{IL}-12$ and $\mathrm{TNF} \alpha$ during ingestion, and deletion of these three kinases together leads to autoimmunity [48]. Although thought to be largely silent, the development of autoimmunity in mice with defects in apoptotic cell clearance suggests that overwhelming of these systems can stimulate an immune response. Whether these mice exhibit evidence of TLR-mediated activation remains to be determined, but the role of TLR activation has been investigated in other models of autoimmunity (discussed below).

The form of apoptotic versus necrotic debris may also be important for TLR recognition of nucleic acids. Proteolytic cleavage of proteins may reveal cryptic antigens or create neoepitopes [49]. Different stages of apoptosis may differentially alter autoantigens, so that early compared with late apoptosis results in different autoantigen fragments $[43,50]$. In addition, necrotic cells induce different signals from those of apoptotic cells; specifically, they activate EKR1, may leak nucleic acid containing immunostimulatory complexes more readily, and induce inflammatory signals in part by releasing high mobility group box (HMGB) proteins (discussed further below) [51,52]. Thus, the type of cell death (apoptotic versus necrotic) and the stage or duration of apoptosis when the dying cell is cleared might affect not only protein autoantigens but also the interactions between proteins and complexed nucleic acids.

\section{High mobility group box protein release from necrotic cells and stimulation of Toll-like receptor 9 by DNA}

HMGB proteins provide a new paradigm for how cell death may be linked to innate immune responses. HMGB1 is a transcriptional regulator that binds more avidly to DNA from apoptotic than to DNA from necrotic cells. When released from necrotic cells it stimulates inflammatory cytokines through the receptor for advanced glycation end-products (RAGE) [52,53]. Cells that are not cleared promptly during apoptosis may undergo secondary necrosis and release cellular components that would normally not gain access to the extracellular milieu. Such cells may release DNA that was tightly bound by HMGB1 [52]. More recent studies suggest that HMGB1 binding to DNA enhances the interaction of the HMGB1/DNA complex to both TLR9 and RAGE, the HMGB1 receptor [54,55]. HMGB1 also augments chromatin IC stimulation of B-cell proliferation. The release of such complexes may explain how mammalian DNA is able to stimulate TLR9. This and other unidentified mechanisms might be responsible for rendering mammalian DNA and RNA from apoptotic and necrotic cells stimulatory to nucleic acid sensing TLRs.

\section{Toll-like receptors in murine models of autoimmunity}

The importance of TLR activation has been studied in several animal models of lupus. In the MRL/Ipr mouse, deletion of the fas gene leads spontaneously to the development of autoantibodies to DNA and snRNPs (Sm), and associated nephritis and dermatitis. Deletion of the TLR9 gene largely blocked the development of anti-DNA antibodies in MRL/lpr mice, but it exacerbated clinical disease [56]. The role played by TLR9 has also been studied in a major histocompatibility complex class II disparate graft-versus-host disease model of SLE, in which TLR9 deficiency once again resulted in lower titers of anti-DNA antibodies but no amelioration of clinical 
nephritis [56]. In yet a third model of SLE that develops in mice expressing mutant phospholipase C2, TLR9 deletion results in increased antinucleolar antibodies, probably directed against RNA-containing small nucleolar RNP (snoRNP), and appears actually to increase the severity of nephritis [57]. Although not conclusive and at odds with the generally accepted role of anti-DNA antibodies in lupus pathogenesis, these studies strongly support the roles of TLRs in the development of autoantibodies, but they suggest that autoimmunity to DNA mediated by TLR9 is not pathogenic but in some cases may actually ameliorate disease. In contrast to these models, TLR9 agonist, CpG oligonucleotide treatment of $\mathrm{MRL}(\mathrm{lpr} / \mathrm{lpr}$ ) mice triggered both anti-DNA antibodies and nephritis, suggesting that the effect of TLR9 may depend on specific features of the particular murine model or on coactivation of other TLRs, such as TLR7 [58].

Studies of TLR7 in murine lupus models emphasize the importance of this TLR in stimulating autoantibodies to RNA/protein complexes and in promoting clinical autoimmune disease. Deletion of TLR7 in MRL/lpr mice blocks the development of anti-snRNP antibodies (Sm), and in contrast to TLR9 deletion it ameliorates clinical disease [59]. The importance of TLR7 in developing autoimmunity to RNA/ protein complexes is further supported by the observation that the $\mathrm{Y}$-linked autoimmune accelerator (Yaa) includes a duplication of TLR7 [60]. Originally identified in BXSB mice, Yaa accelerates autoimmunity in this and other murine models of SLE. In B6 FcyRllb-deleted mice (another murine model of lupus), Yaa leads to markedly accelerated autoimmunity, nephritis, and, notably, a shift from anti-DNA toward anti-nucleolar antibodies. Yaa also markedly accelerates autoimmunity in B6 mice harboring the Sle1, autoimmune haplotype [61]. Together, these data strongly implicate TLR7 in the production of autoantibodies to RNA/protein molecular complexes, such as snRNPs and snoRNPs. These studies also suggest that these autoantibodies and/or other effects of TLR7 activation contribute to SLE disease manifestations, including nephritis.

\section{Viral infections and innate immunity}

A relationship between TLR activation, IFN, and autoimmunity has also been shown in infectious illnesses. Indeed, lupus exhibits remarkable similarities to and might be triggered by infectious TLR activation. Type I IFN production is a key step in fighting viral infections, and viral defenses develop elaborate methods for inhibiting IFN or its signaling [62]. For example, in hepatitis $\mathrm{C}$ viral proteins NS2 and NS3/4A inhibit IFN production, possibly contributing to the chronic survival of the hepatitis $\mathrm{C}$ virus in the host [63]. Notably, although such patients' infections often respond to IFN, these IFNtreated patients occasionally develop antinuclear antibodies and SLE. In murine models autoimmunity can be induced by TLR3 activation within the context of a T-cell viral or autoantigen stimulus $[64,65]$. Thus, TLRs can augment immune responses to infectious organisms and such activity might lead to autoimmunity. Although infectious diseases, such as Epstein-Barr viral infections have been suggested to play roles in SLE [66], an infectious trigger has not yet been proven. These studies also highlight the potential complementary roles played by the adaptive and innate immune systems in both responding to infections and inducing autoimmunity.

\section{Theapeutic implications \\ Toll-like receptors as therapeutic targets}

As data linking TLR activation and IFN- $\alpha$ secretion accumulate, methods for manipulating these receptors has advanced at an equal or even faster pace. The excitement surrounding activating TLRs for treatment of infectious and oncologic diseases, and in particular in vaccine development, assures an enduring interest in TLR therapeutics that extends to autoimmunity [67]. For autoimmune disease, of course, the goal is different of course. For SLE, anticipated therapeutics will inhibit TLR activation. Much has been learned about both the activation and inhibition of the nucleic acid TLRs through relatively straightforward experiments by modifying the sequence and structural motifs in synthetic oligonucleotides. Inhibitory oligonucleotides have been described for both TLR7 and TLR9 $[68,69]$.

The differences in effector cell expression of TLRs should provide some specificity for the cell type(s) targeted as selective antagonists of TLR7, TLR8, and TLR9 are developed as human therapeutic agents. For example, TLR7 and TLR9 are found on B cells and pDCs but not on monocytes or cDCs, which instead express TLR8 (as well as other TLRs). In addition, different TLR therapies might be designed based on autoantibody profiles and/or disease manifestations. For example, patients with anti-DNA antibodies and lupus nephritis might respond to TLR9 inhibition, whereas patients with anti-snRNP or Ro antibodies might respond better to TLR7/8 inhibition. However, murine studies remain unclear at this point regarding the precise role of TLR9 in pathogenesis. Data showing enhanced disease in TLR9-deleted mice may reflect a permissive effect for TLR7activated pathways. Thus, we expect and anticipate that models of lupus in mice deleted of both TLR7 and TLR9 with provide additional insight into the potential therapeutic role of TLR9 inhibition in lupus.

\section{Targeting type I interferons in systemic lupus erythematosus}

The parallel discoveries of the role of TLRs in stimulating type I IFNs, of pDCs as the primary source of this cytokine, and of the IFN-signature in lupus patients by microarray analyses $[37,38]$ have identified the type I IFN as another promising therapeutic target, which is under active investigation for treatment of SLE. Because the IFN- $\alpha$ family includes 13 isotypes, its inhibition may prove challenging, but several pharmaceutical companies are developing multi-isotype IFN- $\alpha$ blocking antibodies for therapy in humans, as well as antibodies to the unique type I IFN receptor $[70,71]$. 


\section{Conclusion}

Nucleic acid/protein ICs from lupus patients act as immune adjuvants in vitro and play key roles in murine models of lupus. The activity of these ICs appears largely to be mediated by intracellular, nucleic acid binding TLRs, stimulating B-cell maturation and $\mathrm{pDC}$ secretion of IFN- $\alpha$. These findings provide a new framework for understanding lupus pathogenesis and suggest new therapeutic targets, some of which might be targeted by already identified and readily synthesized oligonucleotides. Ongoing investigations should provide further insights into the source of nucleic acid/protein molecular complexes, how these complexes enter the cell, and why these complexes become immune stimulants in lupus but not normal individuals.

\section{Competing interests}

AM-R has applied for a US patent application $(10 / 487,885)$ entitled, Method and Composition for Treating Immune Complex Associated Disorders. Corresponding foreign applications have been licensed and provide royalty income.

\section{References}

1. DeGiorgio LA, Konstantinov KN, Lee SC, Hardin JA, Volpe BT, Diamond B: A subset of lupus anti-DNA antibodies crossreacts with the NR2 glutamate receptor in systemic lupus erythematosus. Nat Med 2001, 7:1189-1193.

2. Lapteva L, Nowak M, Yarboro CH, Takada K, Roebuck-Spencer T, Weickert T, Bleiberg J, Rosenstein D, Pao M, Patronas N, et al:: Anti-N-methyl-D-aspartate receptor antibodies, cognitive dysfunction, and depression in systemic lupus erythematosus. Arthritis Rheum 2006, 54:2505-2514.

3. Stein AJ, Fuchs G, Fu C, Wolin SL, Reinisch KM: Structural insights into RNA quality control: the Ro autoantigen binds misfolded RNAs via its central cavity. Cell 2005, 121:529-539.

4. James JA, Gross T, Scofield RH, Harley JB: Immunoglobulin epitope spreading and autoimmune disease after peptide immunization: Sm B/B'-derived PPPGMRPP and PPPGIRGP induce spliceosome autoimmunity. J Exp Med 1995, 181:453461.

5. Fatenejad S, Mamula MJ, Craft J: Role of intermolecular/ intrastructural B- and T-cell determinants in the diversification of autoantibodies to ribonucleoprotein particles. Proc Natl Acad Sci USA 1993, 90:12010-12014.

6. Deshmukh US, Bagavant H, Sim D, Pidiyar V, Fu SM: A SmD peptide induces better antibody responses to other proteins within the small nuclear ribonucleoprotein complex than to $\mathrm{SmD}$ protein via intermolecular epitope spreading. J Immunol 2007, 178:2565-2571.

7. Deshmukh US, Bagavant H, Lewis J, Gaskin F, Fu SM: Epitope spreading within lupus-associated ribonucleoprotein antigens. Clin Immuno/ 2005, 117:112-120.

8. Lu L, Kaliyaperumal A, Boumpas DT, Datta SK: Major peptide autoepitopes for nucleosome-specific T cells of human lupus. J Clin Invest 1999, 104:345-355.

9. Ahmad-Nejad P, Hacker H, Rutz M, Bauer S, Vabulas RM, Wagner H: Bacterial CpG-DNA and lipopolysaccharides activate Toll-like receptors at distinct cellular compartments. Eur $\mathrm{J}$ Immunol 2002, 32:1958-1968.

10. Lafyatis $R$, York $M$, Marshak-Rothstein A: Antimalarial agents: closing the gate on Toll-like receptors? Arthritis Rheum 2006, 54:3068-3070.

11. Parroche P, Lauw FN, Goutagny N, Latz E, Monks BG, Visintin A, Halmen KA, Lamphier M, Olivier M, Bartholomeu DC, et al:: Malaria hemozoin is immunologically inert but radically enhances innate responses by presenting malaria DNA to Toll-like receptor 9. Proc Natl Acad Sci USA 2007, 104:19191924.

12. Stacey KJ, Young GR, Clark F, Sester DP, Roberts TL, Naik S, Sweet MJ, Hume DA: The molecular basis for the lack of immunostimulatory activity of vertebrate DNA. J Immunol 2003, 170:3614-3620.

13. Gursel I, Gursel M, Yamada H, Ishii KJ, Takeshita F, Klinman DM: Repetitive elements in mammalian telomeres suppress bacterial DNA-induced immune activation. J Immunol 2003, 171: 1393-1400.

14. Cornacchia E, Golbus J, Maybaum J, Strahler J, Hanash S, Richardson B: Hydralazine and procainamide inhibit $T$ cell DNA methylation and induce autoreactivity. J Immunol 1988, 140:2197-2200.

15. Vallin H, Blomberg S, Alm GV, Cederblad B, Ronnblom L: Patients with systemic lupus erythematosus (SLE) have a circulating inducer of interferon-alpha (IFN-alpha) production acting on leucocytes resembling immature dendritic cells. Clin Exp Immunol 1999, 115:196-202.

16. Bave U, Alm GV, Ronnblom L: The combination of apoptotic U937 cells and lupus IgG is a potent IFN-alpha inducer. J Immunol 2000, 165:3519-3526.

17. Diebold SS, Kaisho T, Hemmi H, Akira S, Reis e Sousa C: Innate antiviral responses by means of TLR7-mediated recognition of single-stranded RNA. Science 2004, 303:1529-1531.

18. Heil $F$, Hemmi $H$, Hochrein $H$, Ampenberger $F$, Kirschning $C$, Akira S, Lipford G, Wagner H, Bauer S: Species-specific recognition of single-stranded RNA via toll-like receptor 7 and 8 . Science 2004, 303:1526-1529.

19. Vollmer J, Tluk S, Schmitz C, Hamm S, Jurk M, Forsbach A, Akira S, Kelly KM, Reeves WH, Bauer S, Krieg AM: Immune stimulation mediated by autoantigen binding sites within small nuclear RNAs involves Toll-like receptors 7 and 8. J Exp Med 2005, 202:1575-1585.

20. Kariko K, Buckstein M, Ni H, Weissman D: Suppression of RNA recognition by Toll-like receptors: the impact of nucleoside modification and the evolutionary origin of RNA. Immunity 2005, 23:165-175.

21. Leadbetter EA, Rifkin IR, Hohlbaum AM, Beaudette BC, Shlomchik MJ, Marshak-Rothstein A: Chromatin-IgG complexes activate $B$ cells by dual engagement of IgM and Toll-like receptors. Nature 2002, 416:603-607.

22. Viglianti GA, Lau CM, Hanley TM, Miko BA, Shlomchik MJ, Marshak-Rothstein A: Activation of autoreactive $B$ cells by $\mathrm{CpG}$ dsDNA. Immunity 2003, 19:837-847.

23. Bave U, Magnusson M, Eloranta ML, Perers A, Alm GV, Ronnblom $\mathrm{L}$ : Fc gamma Rlla is expressed on natural IFN-alpha-producing cells (plasmacytoid dendritic cells) and is required for the IFN-alpha production induced by apoptotic cells combined with lupus IgG. J Immunol 2003, 171:3296-3302.

24. Means TK, Latz E, Hayashi F, Murali MR, Golenbock DT, Luster AD: Human lupus autoantibody-DNA complexes activate DCs through cooperation of CD32 and TLR9. J Clin Invest 2005, 115:407-417.

25. Boule MW, Broughton C, Mackay F, Akira S, Marshak-Rothstein A, Rifkin IR: Toll-like receptor 9-dependent and -independent dendritic cell activation by chromatin-immunoglobulin G complexes. J Exp Med 2004, 199:1631-1640.

26. Savarese E, Chae OW, Trowitzsch S, Weber G, Kastner B, Akira S, Wagner H, Schmid RM, Bauer S, Krug A: U1 small nuclear ribonucleoprotein immune complexes induce type I interferon in plasmacytoid dendritic cells through TLR7. Blood 2006, 107:3229-3234.

27. Wardemann H, Yurasov S, Schaefer A, Young JW, Meffre E, Nussenzweig MC: Predominant autoantibody production by early human B cell precursors. Science 2003, 301:1374-1377.

28. Bekeredjian-Ding IB, Wagner M, Hornung V, Giese T, Schnurr M, Endres S, Hartmann G: Plasmacytoid dendritic cells control TLR7 sensitivity of naive B cells via type I IFN. J Immuno/ 2005, 174:4043-4050.

29. Berland R, Fernandez L, Kari E, Han JH, Lomakin I, Akira S, Wortis $\mathrm{HH}$, Kearney JF, Ucci AA, Imanishi-Kari T: Toll-like receptor 7dependent loss of $B$ cell tolerance in pathogenic autoantibody knockin mice. Immunity 2006, 25:429-440.

30. He B, Qiao X, Cerutti A: CpG DNA induces IgG class switch DNA recombination by activating human $B$ cells through an innate pathway that requires TLR9 and cooperates with IL-10. $\mathrm{J}$ Immunol 2004, 173:4479-4491.

31. Chan OT, Madaio MP, Shlomchik MJ: The central and multiple roles of B cells in lupus pathogenesis. Immunol Rev 1999, 169:107-121. 
32. Liu YJ: IPC: professional type 1 interferon-producing cells and plasmacytoid dendritic cell precursors. Annu Rev Immunol 2005, 23:275-306.

33. Ronnblom L, Alm GV: A pivotal role for the natural interferon alpha-producing cells (plasmacytoid dendritic cells) in the pathogenesis of lupus. J Exp Med 2001, 194:F59-F63.

34. Bekeredjian-Ding I, Roth SI, Gilles S, Giese T, Ablasser A, Hornung V, Endres S, Hartmann G: T cell-independent, TLRinduced IL-12p70 production in primary human monocytes. J Immunol 2006, 176:7438-7446.

35. Peng SL, Moslehi J, Craft J: Roles of interferon-gamma and interleukin-4 in murine lupus. J Clin Invest 1997, 99:19361946.

36. Ozmen L, Roman D, Fountoulakis M, Schmid G, Ryffel B, Garotta G: Experimental therapy of systemic lupus erythematosus: the treatment of NZB/W mice with mouse soluble interferongamma receptor inhibits the onset of glomerulonephritis. Eur $J$ Immunol 1995, 25:6-12.

37. Baechler EC, Batliwalla FM, Karypis G, Gaffney PM, Ortmann WA, Espe KJ, Shark KB, Grande WJ, Hughes KM, Kapur V, et al.: Interferon-inducible gene expression signature in peripheral blood cells of patients with severe lupus. Proc Natl Acad Sci USA 2003, 100:2610-2615.

38. Crow MK, Kirou KA, Wohlgemuth J: Microarray analysis of interferon-regulated genes in SLE. Autoimmunity 2003, 36:481490.

39. Hron JD, Peng SL: Type I IFN protects against murine lupus. J Immunol 2004, 173:2134-2142.

40. Lauber K, Blumenthal SG, Waibel M, Wesselborg S: Clearance of apoptotic cells: getting rid of the corpses. Mol Cell 2004, 14:277-287.

41. Mevorach D, Zhou JL, Song X, Elkon KB: Systemic exposure to irradiated apoptotic cells induces autoantibody production. $J$ Exp Med 1998, 188:387-392.

42. Gilkeson GS, Grudier JP, Karounos DG, Pisetsky DS: Induction of anti-double stranded DNA antibodies in normal mice by immunization with bacterial DNA. J Immunol 1989, 142:14821486.

43. Wu Y, Tibrewal N, Birge RB: Phosphatidylserine recognition by phagocytes: a view to a kill. Trends Cell Biol 2006, 16:189-197.

44. Botto M, Dell'Agnola C, Bygrave AE, Thompson EM, Cook HT, Petry F, Loos M, Pandolfi PP, Walport MJ: Homozygous C1q deficiency causes glomerulonephritis associated with multiple apoptotic bodies. Nat Genet 1998, 19:56-59.

45. Mevorach D, Mascarenhas JO, Gershov D, Elkon KB: Complement-dependent clearance of apoptotic cells by human macrophages. J Exp Med 1998, 188:2313-2320.

46. Peng $Y$, Kowalewski R, Kim S, Elkon KB: The role of IgM antibodies in the recognition and clearance of apoptotic cells. Mol Immunol 2005, 42:781-787.

47. Hanayama R, Tanaka M, Miyasaka K, Aozasa K, Koike M, Uchiyama $Y$, Nagata S: Autoimmune disease and impaired uptake of apoptotic cells in MFG-E8-deficient mice. Science 2004, 304:1147-1150.

48. Lu Q, Lemke G: Homeostatic regulation of the immune system by receptor tyrosine kinases of the Tyro 3 family. Science 2001, 293:306-311.

49. Hall JC, Casciola-Rosen L, Rosen A: Altered structure of autoantigens during apoptosis. Rheum Dis Clin North Am 2004, 30:455-471, vii.

50. Wu X, Molinaro C, Johnson N, Casiano CA: Secondary necrosis is a source of proteolytically modified forms of specific intracellular autoantigens: implications for systemic autoimmunity. Arthritis Rheum 2001, 44:2642-2652.

51. Patel VA, Longacre A, Hsiao K, Fan H, Meng F, Mitchell JE, Rauch J. Ucker DS, Levine JS: Apoptotic cells, at all stages of the death process, trigger characteristic signaling events that are divergent from and dominant over those triggered by necrotic cells: Implications for the delayed clearance model of autoimmunity. J Biol Chem 2006, 281:4663-4670.

52. Scaffidi $P$, Misteli T, Bianchi ME: Release of chromatin protein HMGB1 by necrotic cells triggers inflammation. Nature 2002 , 418:191-195

53. DeMarco RA, Fink MP, Lotze MT: Monocytes promote natural killer cell interferon gamma production in response to the endogenous danger signal HMGB1. Mol Immunol 2005, 42: 433-444.
54. Ivanov S, Dragoi AM, Wang X, Dallacosta C, Louten J, Musco G, Sitia G, Yap GS, Wan Y, Biron CA, et al.: A novel role for HMGB1 in TLR9-mediated inflammatory responses to CpGDNA. Blood 2007, 110:1970-1981.

55. Tian J, Avalos AM, Mao SY, Chen B, Senthil K, Wu H, Parroche P, Drabic S, Golenbock D, Sirois C, et al.: Toll-like receptor 9dependent activation by DNA-containing immune complexes is mediated by HMGB1 and RAGE. Nat Immuno/ 2007, 8:487496.

56. Ma Z, Chen F, Madaio MP, Cohen PL, Eisenberg RA: Modulation of autoimmunity by TLR9 in the chronic graft-vs-host model of systemic lupus erythematosus. J Immunol 2006, 177:74447450.

57. Yu P, Wellmann U, Kunder S, Quintanilla-Martinez L, Jennen L, Dear N, Amann K, Bauer S, Winkler TH, Wagner H: Toll-like receptor 9-independent aggravation of glomerulonephritis in a novel model of SLE. Int Immuno/ 2006, 18:1211-1219.

58. Pawar RD, Patole PS, Ellwart A, Lech M, Segerer S, Schlondorff $\mathrm{D}$, Anders $\mathrm{HJ}$ : Ligands to nucleic acid-specific toll-like receptors and the onset of lupus nephritis. J Am Soc Nephrol 2006, 17:3365-3373.

59. Christensen SR, Shupe J, Nickerson K, Kashgarian M, Flavell RA Shlomchik MJ: Toll-like receptor 7 and TLR9 dictate autoantibody specificity and have opposing inflammatory and regulatory roles in a murine model of lupus. Immunity 2006, 25: 417-428.

60. Pisitkun P, Deane JA, Difilippantonio MJ, Tarasenko T, Satterthwaite $A B$, Bolland $S$ : Autoreactive $B$ cell responses to RNArelated antigens due to TLR7 gene duplication. Science 2006, 312:1669-1672.

61. Subramanian $\mathrm{S}$, Tus K, Li QZ, Wang A, Tian XH, Zhou J, Liang C, Bartov G, McDaniel LD, Zhou XJ, et al.: A Tir7 translocation accelerates systemic autoimmunity in murine lupus. Proc Natl Acad Sci USA 2006, 103:9970-9975.

62. Katze MG, He Y, Gale M Jr: Viruses and interferon: a fight for supremacy. Nat Rev Immunol 2002, 2:675-687.

63. Kaukinen P, Sillanpaa M, Kotenko S, Lin R, Hiscott J, Melen K, Julkunen I: Hepatitis C virus NS2 and NS3/4A proteins are potent inhibitors of host cell cytokine/chemokine gene expression. Virol J 2006, 3:66.

64. Lang KS, Georgiev $\mathrm{P}$, Recher $\mathrm{M}$, Navarini AA, Bergthaler A, Heikenwalder M, Harris NL, Junt T, Odermatt B, Clavien PA, et al.: Immunoprivileged status of the liver is controlled by Toll-like receptor 3 signaling. J Clin Invest 2006, 116:2456-2463.

65. Colonna M: Toll-like receptors and IFN-alpha: partners in autoimmunity. J Clin Invest 2006, 116:2319-2322.

66. McClain MT, Heinlen LD, Dennis GJ, Roebuck J, Harley JB, James $J A$ : Early events in lupus humoral autoimmunity suggest initiation through molecular mimicry. Nat Med 2005, 11:85-89.

67. Krieg AM: Therapeutic potential of Toll-like receptor 9 activation. Nat Rev Drug Discov 2006, 5:471-484.

68. Lenert PS: Targeting Toll-like receptor signaling in plasmacytoid dendritic cells and autoreactive B cells as a therapy for lupus. Arthritis Res Ther 2006, 8:203.

69. Barrat FJ, Meeker T, Gregorio J, Chan JH, Uematsu S, Akira S, Chang B, Duramad O, Coffman RL: Nucleic acids of mammalian origin can act as endogenous ligands for Toll-like receptors and may promote systemic lupus erythematosus. $J$ Exp Med 2005, 202:1131-1139.

70. Anti-IFN alpha [http://www.gene.com/gene/pipeline/status/ immunology/antiifn/index.jsp]

71. Anti-IFNa monoclonal antibody [http://www.medimmune.com/ pipeline/ifna.asp]. 